\title{
METAHEURISTICS FOR THE WASTE COLLECTION VEHICLE ROUTING PROBLEM IN URBAN AREAS
}

\author{
UDC 004.7:628.463
}

\section{Aleksandar Stanković, Danijel Marković, Goran Petrović, Žarko Ćojbašić}

\author{
Faculty of Mechanical Engineering, University of Niš, Serbia
}

\begin{abstract}
This paper presents a methodology for solving the municipal waste collection problem in urban areas. The problem is treated as a distance-constrained capacitated vehicle routing problem for municipal waste collection (DCCVRP-MWC). To solve this problem, four meta-heuristic algorithms were used: Genetic algorithm (GA), Simulated annealing (SA), Particle swarm optimization (PSO) and Ant colony optimization (ACO). Vehicle guidance plays a huge role in large transportation companies, and with this test, we propose one of several algorithms for solving urban waste collection problems.
\end{abstract}

Key words: vehicle routing problem, municipal waste, meta-heuristic, logistic model.

\section{INTRODUCTION}

In order to achieve the optimization of waste collection, the management method is divided into three levels of management, waste management optimization [1]. The first strategic level involves the optimization of the waste management system by the choice of waste collection technology. The second tactical level represents the optimization of the waste management system by selecting the locations of the transshipment stations, while the third operational level involves the optimization of the management system for selecting the "routes" of waste collection and transportation. In this paper, the operational level is considered through the optimization of the routes of movement of municipal waste collection and transportation vehicles. The optimization of commuting routes for municipal waste collection vehicles is one of the groups of vehicle routing problems, which is in the scientific literature known as the Vehicle Routing Problem - VRP. It was first mentioned in 1959 by Dantzig and Ramser [2]. Since then, the VRP problem has been increasingly applied in solving various problems and has had great economic importance for reducing the operating costs of distribution systems. One of the main motivations for research on

Received January 21, 2020 / Accepted April 23, 2020

Corresponding author: Žarko Ćojbašić

Faculty of Mechanical Engineering, University of Niš, Aleksandra Medvedeva 14, 18000 Niš, Serbia

E-mail: zcojba@ni.ac.rs 
VRP problems is the improvement of the municipal waste disposal system through the optimization of the collection in the transportation of municipal waste in urban areas. The problem was discussed on the territory of Nis in Serbia, and meta-heuristic algorithms were proposed for solving the problem. Such a case study is very interesting because of its complexity and belongs to a group of severe non-deterministic polynomial-time problems (NP). Numerous papers and research on a similar topic can be found in the scientific literature. Teixeira and his associates [3] are just one of many scientists involved in solving VRP problems. In their research, they have shown that optimizing the movement of vehicles while collecting municipal waste can reduce travel time by about $29 \%$. Something similar to this, Tavares [4] says in his work that with the help of optimization there is a possibility of reducing spent fuel when collecting municipal waste by about $12 \%$.

In this paper, the problem is seen as the distance-constrained capacitated vehicle routing problem for municipal waste collection (DCCVRP-MWC). By choosing optimal routes for communal waste collection vehicles, direct savings are achieved by reducing the distance and time spent, as well as by reducing the number of vehicles and workers. When it comes to direct savings, it should be noted that this paper specifically refers to the reduction of the number of vehicles, the reduction of the number and length of routes, the maximum utilization of vehicles when choosing a vehicle path in terms of vehicle capacity from the starting point to the endpoint, and reducing the time spent in the process of collecting communal waste on a defined transport network.

In design routes for municipal waste collection vehicles, the problem must be properly defined. When defining a real problem, it is necessary to have data on the quantities of municipal waste, geographical and traffic characteristics of the space, defined number of vehicles and many other realistic parameters that are necessary for testing. After defining and understanding the problem, it is necessary to select and adjust a mathematical model with certain constraints in order to solve the defined problem within a reasonable time interval. The paper aims to propose a defined meta-heuristic algorithm as well as to develop logistic models for municipal waste management by selecting optimal routes with defined constraints when collecting and transporting municipal waste in an urban environment in the city of Niš.

\section{MATHEMATICAL FORMULATION OF THE DCCVRP-MWC}

The DCCVRP for municipal waste collection (DCCVRP-MWC) can be expressed by using the basic symbols from the theory of graphs in the following manner. Let a full graph be defined by the following equation (1) [5]:

$$
G=(V, A, D, T, Q, S)
$$

where: $V=\{1, \ldots, n\}$ is the set of nodes, $A$ is the set of arcs, $D=\left[d_{i j}\right]$ is the matrix of the shortest distances for $A, T=\left[t_{i j}\right]$ is the matrix of the travelling time in $\operatorname{arc} A$ without the location service time, $Q=\left(q_{1}, q_{2}, \ldots, q_{n}\right)$ is the demand in nodes $V$, and $S=\left(s_{1}, s_{2}, \ldots, s_{n}\right)$ are the times spent in nodes $V$.

In this paper, nodes $i=(2, \ldots, n)$ represent the locations of waste containers $N$ where the waste generated by a certain amount of users is disposed of. The node with index 1 represents the depot, i.e. the landfill from which the vehicles begin their operation. The 
distance matrix $d_{i j}$ is connected with the node $(i, j) \in A$ and it represents the shortest possible distance between the node $i$ and the node $j$. If $d_{i j}=d_{j i}$ for every $(i, j) \in \mathrm{A}$, then the problem is called the symmetrical DCCVRP-MWC. In the opposite case, we have the asymmetrical DCCVRP-MWC. This paper deals with a symmetrical DCCVRP-MWC. For the matrix of shortest distances $D$ and the matrix of the movement time in branch $T$, the following inequalities are valid ( 2 and 3 , respectively):

$$
\begin{aligned}
& d_{i h}+d_{h j}>d_{i j} \\
& \forall i, j, h \in V, h \neq i \neq j \\
& t_{i h}+t_{h j}>t_{i j} \\
& \forall i, j, h \in V, h \neq i \neq j
\end{aligned}
$$

In previous equations $d$ denotes distance, $t$ denotes time and $i, j$ and $h$ are nodes. When the distance of the branch, i.e. the distance from the node $i$ to the node $j$, is expressed in the travelling time $T$, then the service time related to each of the nodes is added to that time, and this service time represents the time that a vehicle spends in a node. The times spent in nodes $\left(w_{i j}\right)$ are calculated by multiplying the number of containers $\left(N_{k}\right)$ with the time used to empty a container $\left(s_{i}\right)$, i.e. using expression (4):

$$
w_{i j}=N_{k i} \cdot s_{i}
$$

When the times spent in nodes are calculated, then one can calculate the travelling times $\left(t_{i j}\right)$ using the expression (5):

$$
t_{i j}=t_{i j}+\frac{w_{i j}}{2}+\frac{w_{j i}}{2}
$$

where $t_{i j}^{\prime}$ is the time of travelling from the node $i$ to the node $j$ without the time spent in the nodes themselves.

Solving the DCCVRP-MWC means determining the $r$ routes (each route is connected to only one vehicle), where the total travelled distance in a route has to be minimal. The total travelled distance is obtained as the sum of the distances in each of the branches that belong to a route. In this paper, one vehicle collects all the waste from all of the locations.

The solution should meet the following demands:

- each route has to start and end in the depot (landfill),

- each node participates in only one route,

- the sum of the volume of waste in the nodes serviced in one route must not be greater than the vehicle capacity $Q$,

- the sum of the travelling time in a route must not be greater than the maximal allowed time spent on the route $T_{r}$.

The following notation was used to define the mathematical formulation of DCCVRP$M W C$ :

$m-$ maximum number of vehicles used, for DCCVRP-MWC $m=1$,

$n$ - number of nodes from which waste is recovered,

$V$ - set of nodes, $V=\{1,2, \ldots, n\}$,

$V_{0}$ - depot, the place from which the vehicle departs, 
$Q$ - maximum vehicle capacity,

$N_{k i}$ - number of containers in node $i(i \in V)$,

$q_{i}$ - amount of waste in node $i(i \in V)$; the amount of waste in the depot is zero,

$t_{i j}$ - time required to cross the distance between node $i$ and node $j(i, j \in V)$,

$t_{i j}^{\prime}$ - the time required to travel the distance between node $i$ and node $j$ without the dwell time in nodes $(i, j \in V)$,

$c_{i j}-$ transport cost between node $i$ and node $j(i, j \in V)$, assuming cij $=\mathrm{tij}$,

$w_{i}$ - waiting time at $i$-node,

$s_{i}$ - time of service of node $i(i \in V)$, ie time of empty of container of node $i$,

$T_{r}$ - maximum allowed travel time for a vehicle on route $\mathrm{r}$.

Variables decision:

$$
\begin{aligned}
& x_{i j m}\left\{\begin{array}{l}
1, \text { if the vehicle } m \text { after the node } i \text { visits the node } j, \forall i, j \in V \\
0, \text { otherwise }
\end{array}\right. \\
& z_{j m}\left\{\begin{array}{l}
1, \text { if the vehicle } m \text { visits the node } i, i \in V \\
0, \text { otherwise }
\end{array}\right.
\end{aligned}
$$

Function minimization:

with constraints:

$$
\min F=\sum_{i=0}^{n} \sum_{j=0}^{n} c_{i j} x_{i j}
$$

$$
\begin{gathered}
\sum_{i=0}^{n} x_{i 0}-\sum_{j=0}^{n} x_{0 j}=0 \quad i=0,1, \ldots, n \\
\sum_{i=0}^{n} x_{i j}=1, \quad j=1,2, \ldots, n \\
\sum_{i=1}^{n} q_{i} z_{i} \leq Q \quad i=1,2, \ldots, n \\
\sum_{i=0}^{n} x_{i j} t_{i j} \leq T_{r}, \\
t_{0}=s_{0}=w_{0}=0
\end{gathered}
$$

The function DCCVRP-MWC is indicated by (6). Restriction (7) implies that every vehicle leaving the depot returns to that same depot. The restriction shown in Equation (8) indicates that each node must be visited only once by exactly one vehicle. Constraint (9) implies that the total amount of waste in a node must not exceed the maximum capacity of the vehicle. Constraint (10) represents the maximum time of the route, and that time unless otherwise noted in the depot is $\operatorname{Tr}=0$. Constraint (11) defines that all times in the depot are equal to 0 [6]. 


\section{ALGORITHMS FOR SOLVING THE DCCVRP-MWC}

When solving VRP problems in urban areas, different methods and algorithms are used to obtain optimal results. Given that VRP belongs to a group of NP-difficult problems, the application of classical methods often does not provide solutions within a reasonable time. One reason is to increase potential routes when solving this type of problem, so it is not realistic to expect such algorithms to provide accurate solutions in a reasonable amount of time. The application of classical methods is limited to simple problems only, while for more complex real problems, heuristics or meta-heuristics are used. These methods are recognized today as one of the most practical approaches to solving many complex problems, and this is especially true for solving many real-world problems that are combinatorial in nature, such as the problem of directing vehicles in an urban environment. Meta-heuristic methods basically mimic natural processes such as biological evolution, food-seeking ants, the behavior of bees, find the best harmony, thermodynamic process of annealing metals until mutation of genetic material and mimicking the natural process of gene exchange.

The term meta-heuristics was first proposed by renowned scientist Fred Glover in 1986, while a few years later the author defined meta-heuristics as a set of algorithmic concepts used to define heuristic methods applicable to a wide range of problem-solving [7]. Generally, meta-heuristics can be said to be higher than heuristics. Since this paper addresses the problem of directing vehicles to the collection of municipal waste with the above limitations in terms of capacity and time, it can be assumed that good solutions are applied by using the above limitations based on the defined methods. Four meta-heuristic algorithms are covered in the paper: Genetic Algorithm (GA), Ant Colony Optimization (ACO), Simulated Annealing (SA) and Particle Swarm Optimization (PSO). Below, we will outline the algorithms used to solve the case study. By reviewing the literature, it can be seen that the above algorithms are often applied to solve similar problems $[8,9,10,11]$.

\subsection{Genetic Algorithm}

The GA was developed by John Holland with his collaborators in the 1960s and 1970s [12]. The operation of this algorithm is based on the selection of individuals that will participate in the crossover processes. Changes in the genetic material are possible by mutation, the essence of which is to search as large area as possible and to overcome extreme values. When solving VRP problems using the GA algorithm, it is necessary to adjust the algorithm itself, from the input parameters to the basic objective function [13]. GA within the routing problem setup includes several stages represented by the algorithm, namely: problem setup, individual selection, crossover, mutation, and evaluation.
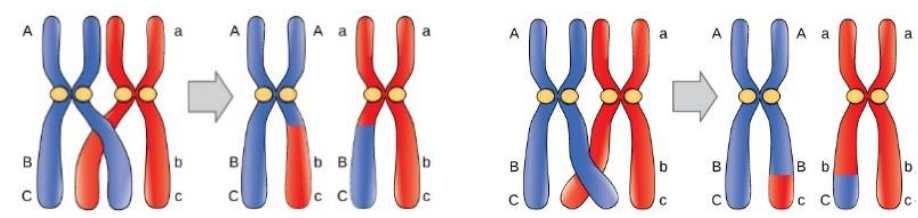

Fig. 1 Graphical representation of the crossing process 
The problem setting involves defining the initial parameters and setting the problem as well as determining the initial population. The selection of individuals from the population according to the goal function represents the fitnesses of the individuals from the population.

GA crossing represents the process of combining existing individuals to obtain brand new individuals, such as parents and their offspring [9]. New individuals inherit the basic traits of their parents. To maintain population size, the most effective way is to get two offspring from two parents to replace.

Mutation involves a random change in the genes of individuals in a population. Mutations are generally applied at the gene level of individuals in a population. This practically means a random change routes order. The basic goal is to get an individual that cannot be obtained in other stages of the search. When a new major appearance of chromosomes is formed based on the previous crossover and mutation phase, the process of selecting their suitability follows. Eligibility, selection, crossover and mutation processes are performed until a predefined number of iterations is reached. The pseudocode of GA is presented in Table 1 [14].

Table 1 Pseudo code of GA

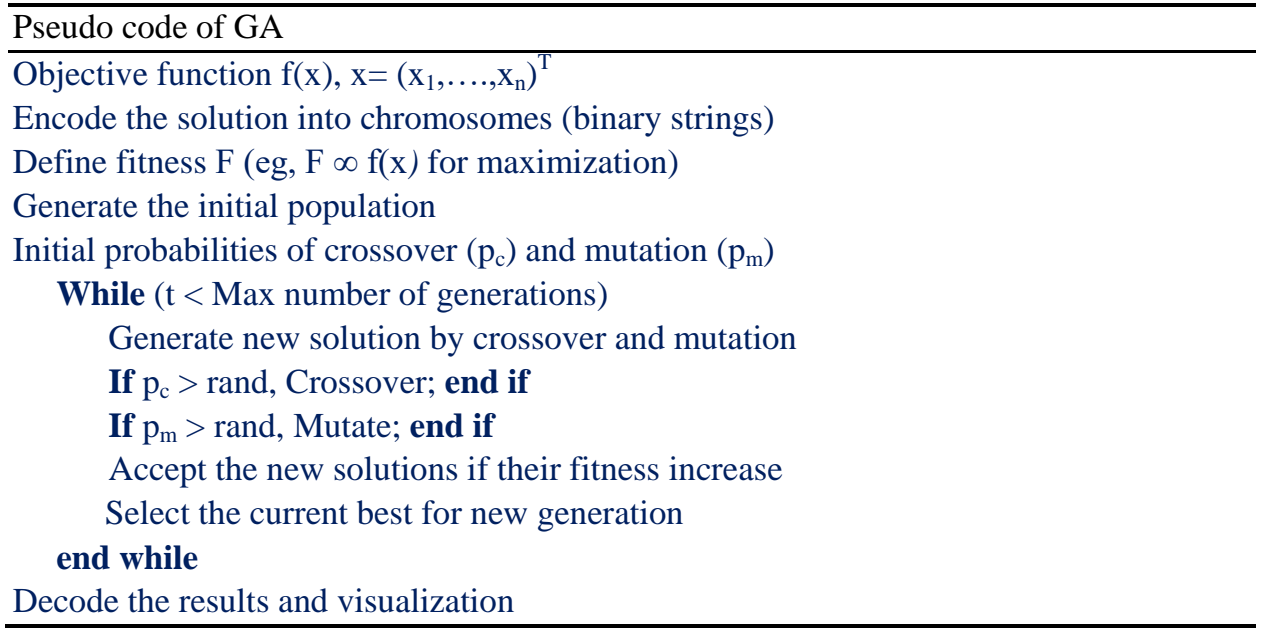

\subsection{Particle Swarm Optimization}

The PSO algorithm was developed as early as in 1995 by Kennedy and Eberhart [15], based on swarm of particles behaviour.

Unlike other meta-heuristic algorithms, PSO operation is particle-based while solution convergence is based on particle orientation. PSO has found great use in the scientific literature in recent years and has proven to be one of the useful algorithms that provide an optimal solution when solving problems with constraints such as this similarity study. It is characterized by one phase during the search for a solution, but also the other two key factors, namely: the rate of particle swarm and the location of the particles. 
PSO is the process of finding the optimal solution that takes place based on input parameters through a series of defined iterations [8]. At the end of each iteration, each particle innovates in its memory the following two values: (a) the best value of the criterion function the particle has ever achieved; (b) the best value of the criterion function that any particle has ever achieved. In this way, the particle takes care of both its achievements and the achievements of the other particles with which it is in the crowd [16].

By determining their best values (up to that point) and the best-revealed value of the entire swarm, all particles change their speeds through which they fly through space into their positions in space of permissible solutions.
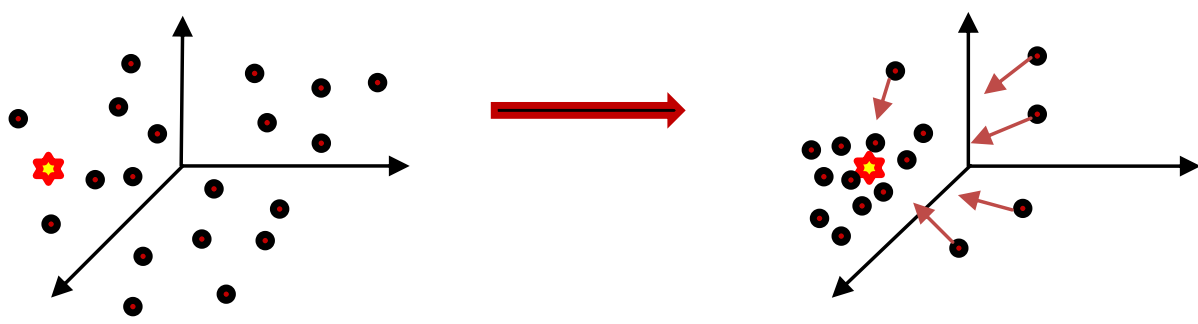

Fig. 2 Finding the optimal solution PSO algorithm

The basic parameters that characterize the PSO algorithm are:

Positions $X_{i}=\left(x_{i 1}, x_{i 2}, \ldots, x_{i D}\right)$ and speed $V_{i}=\left(v_{i 1}, v_{i 2}, \ldots, v_{i D}\right)$ individual particles represent vectors. Position $X_{k+1}^{i} i$ particles in iteration $k+1$ is calculated as follows:

$$
X_{k+1}^{i}=x_{i k}+v_{k+1}^{i} \Delta t,
$$

wherein $V_{k+1}^{i}$ the velocity of the $i$-th particle in iteration $k+1$, a $\Delta t$ unit time interval. Speed $V_{k+1}^{i}$ is equal:

$$
V_{k+1}^{i}=\omega V_{k}^{i}+c_{1} r_{1} *\left(P_{B i}-X_{i k}\right) / \Delta t+c_{1} r_{1} *\left(P_{g}-X_{i k}\right) / \Delta t
$$

wherein:

$\omega \quad$ - "inertia" of a particle.

$r_{1}, r_{2}$ - random numbers (independent of each other) from the unit interval $[0,1]$,

$c_{1}, c_{2}$ - "trust" parameters (parameter $c_{1}$ shows how many particles trust themselves, and parameter $c_{2}$ how many particles trust a group of particles),

$\Delta t \quad$ - unit time interval,

$P_{B i} \quad$ - the best ever detected position of the $i$ particle,

$P_{g} \quad-$ the best ever detected pose of any particle.

Parameters $c_{1}$ and $c_{2}$ can also be implemented as learning parameters since each particle is constantly learning the results of its decisions as well as the best results achieved in the particle group. In this way, particles learn how to make good decisions in the future.

The initial parameters of the PSO algorithm are set independently on the number of iterations and the quality of the obtained solution. The pseudo-code of the PSO algorithm is presented in Table 2 [14]. 
Table 2 Pseudo code of PSO

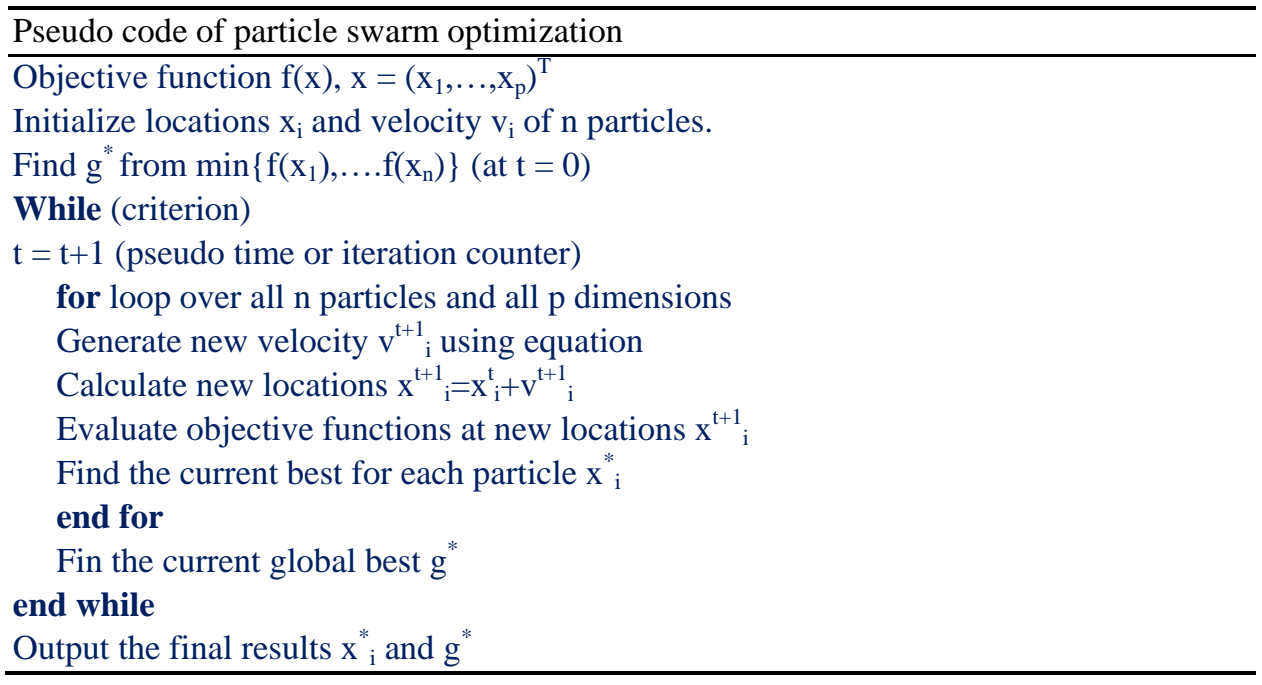

\subsection{Ant Colony Optimization}

ACO algorithm belongs to a group of algorithms that mimics the natural process of moving ants, finding food or the shortest path from point A to point $\mathrm{B}$. This phenomenon of finding the shortest path in a natural environment is a complex search process where ants, as a set of individuals, exchange information about their movements based on the phenomenon of collective intelligence. The movement information of each individual is obtained by leaving a trace in the form of a chemical substance in science known as pheromone [17]. The more ants go along the same route, the more pheromones on that route, which is positive information for each subsequent ant on the correctness of that route. This is how ants interact with each other and, based on this principle of movement of ant colonies, the shortest route is reached.
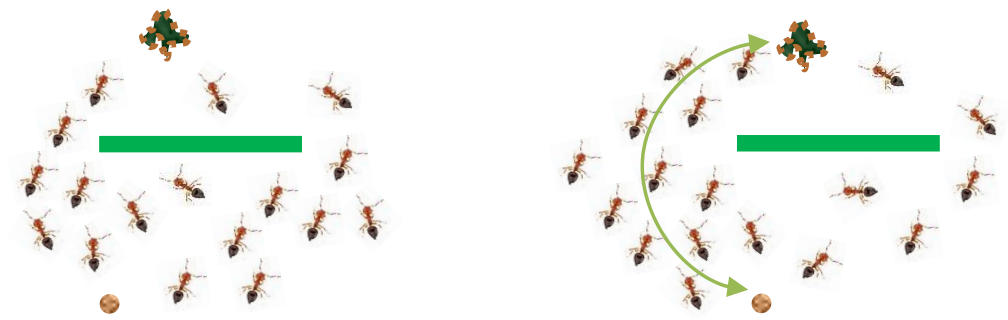

Fig. 3 Natural shortest path search process 
ACO algorithm is a population-based meta-heuristic that is used to solve severe NP problems in our case by solving the multi-constraint vehicle routing problem. Based on the described natural process of moving ants, an ACO algorithm was developed by the well-known scientists Dorigo Menizze and Colorni in 1991, while Dorigo and Stutze later refined this algorithm [18]. This algorithm is represented by the pseudo-code in Table 3 [14].

Table 3 Pseudo code of ACO

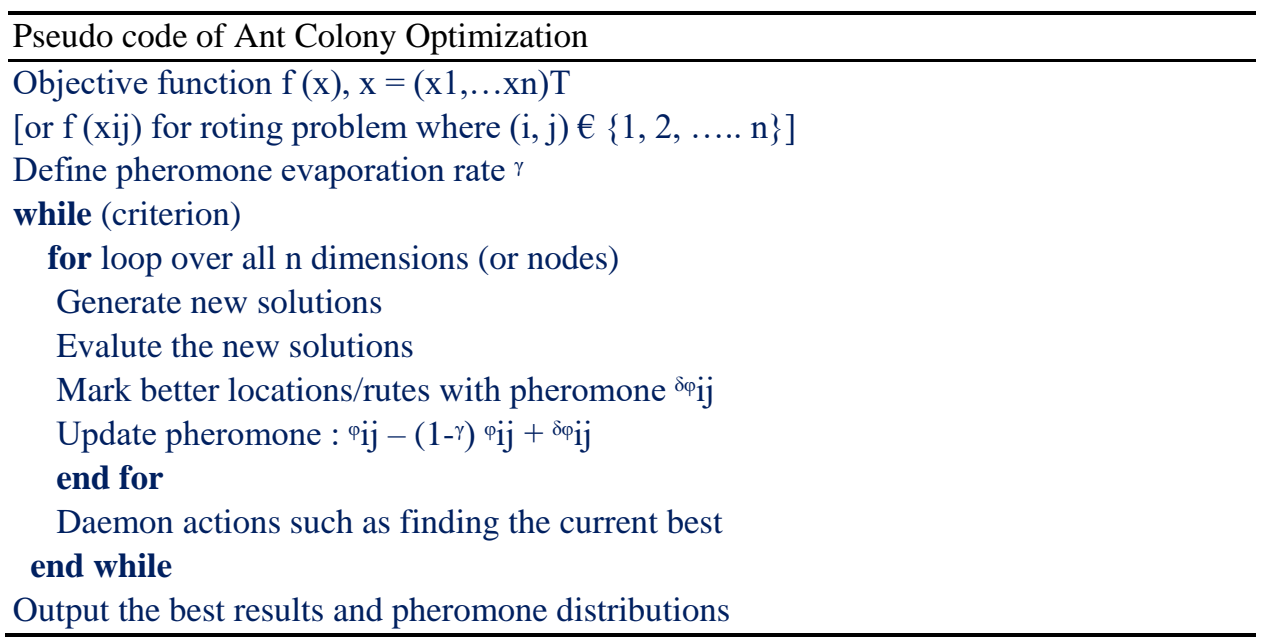

\subsection{Simulated Annealing}

This algorithm is a group of algorithms that are increasingly being used to solve difficult NP problems due to their efficiency in solving them. As could be seen in the previous description, each of them mimics a process, and in this case, it is the process of tempering the material. The basic feature of the SA algorithm is that the temperature of the material is reduced to some permissible state to which the lowest temperature corresponds, while the tempering process of the material involves pre-defining the temperatures at which the material will meet the defined time. Some of the features of this method were given by Madić, as follows [19]: (1) the quality of the solution does not depend on the initial solution, but unless a good initial solution is defined, the time required to obtain the final solution increases significantly, (2) the given variables can be negative, (3) this algorithm can be applied to solve various discrete and contour optimization problems.

The SA algorithm was first proposed in 1983 by renowned scientist Kirkpatrick and his collaborators [20]. The application of the SA algorithm in solving complex optimization problems has prompted other meta-heuristic algorithms to develop and solve similar problems, which can be seen in this paper. The pseudo-code of this SA algorithm is presented in Table 4 [14]. 
Table 4 Pseudo code of SA

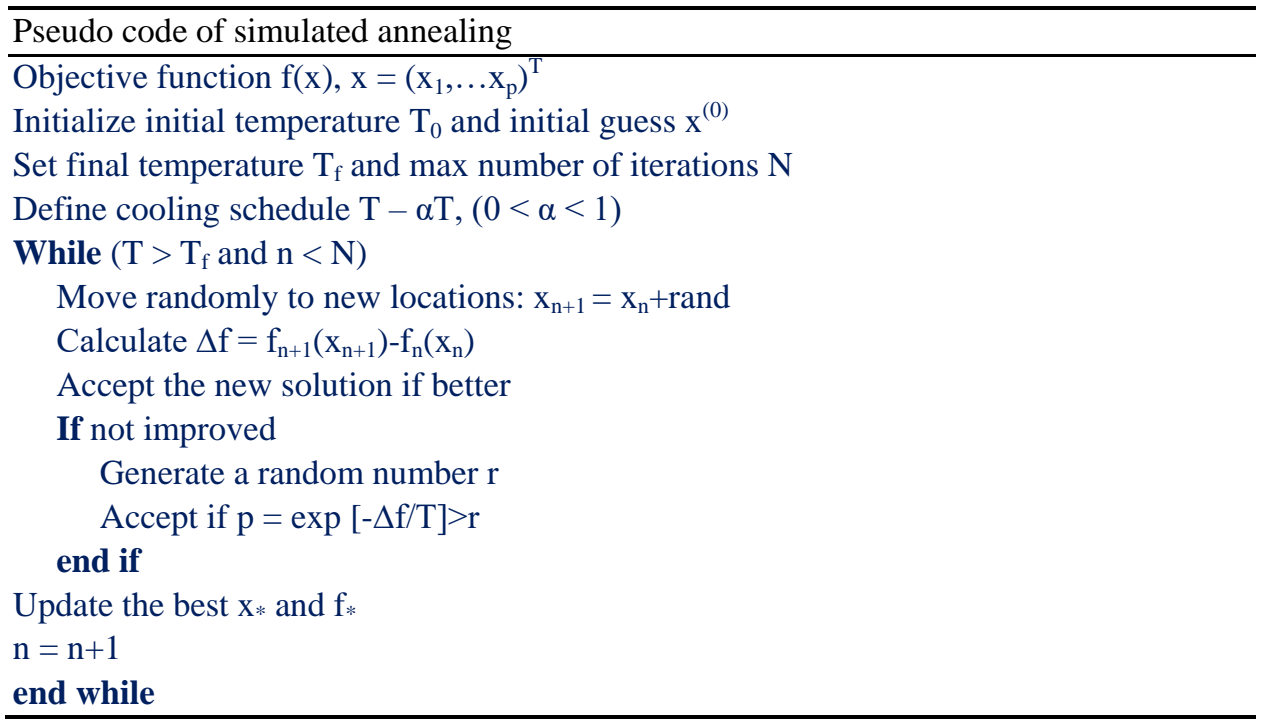

\section{CASE Study}

In this chapter, the problem of solving the vehicles routing of municipal waste collection with a limitation of the capacity and time of service of each route is presented. The main objective of this case study is to optimize vehicle movement routes based on defined metaheuristic algorithms in the form of constraints. The model is defined by a transport network (Figure 4) with a certain number of nodes based on latitude and longitude. The starting node for the departure of an empty vehicle and the back node for re-returning the vehicle for communal waste discharge is called a depot and represents node 1 , while the other nodes are numbered by container locations on the part of the Nis City Territory from 2 to 21 .

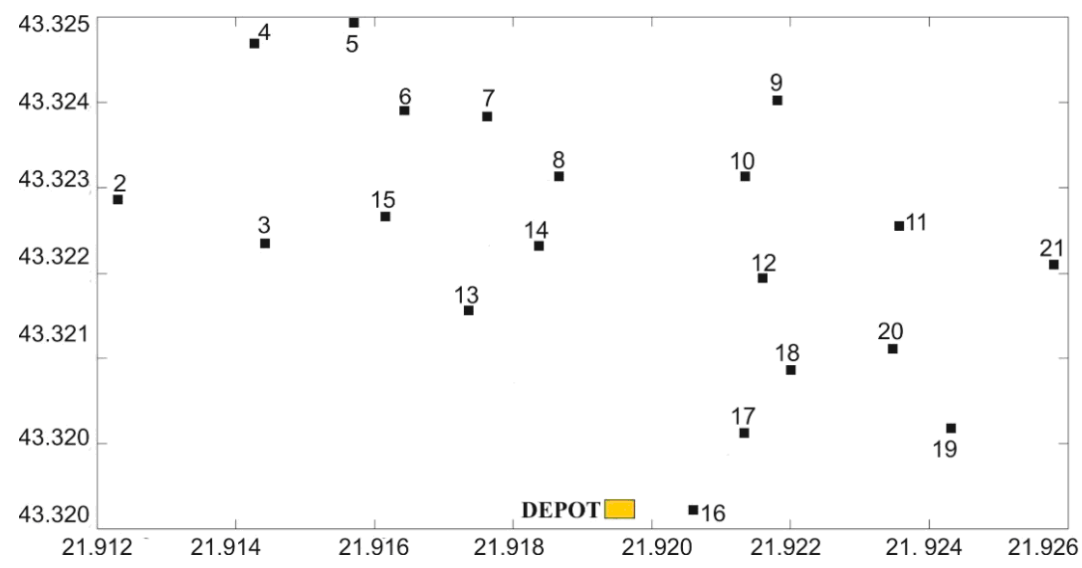

Fig. 4 Graphic transport networks 
In Table 5, in addition to the node coordinates, the number of containers per node for the observed transport network is shown. In locations where there is more than one container, their position is also defined by one node or one coordinate.

The vehicle leaving the depot is assumed to be always empty. Prior to the departure of the vehicle from the depot, in addition to the capacity of the vehicle $Q$, the time limit of the Trio route was defined. After the first node has been serviced, the capacity of the vehicle and the route time will be checked. If the capacity is not filled and the duration of the route is not exceeded, another node is served. Also, if one of the restrictions is exceeded the vehicle returns to the depot for emptying. This process is repeated until all the nodes for the observed transport network are served. In addition, partial servicing is not possible, which means that only a part of the demand is met in the node.

In this model, the distance from node $i$ to node $j$ is expressed in route duration. This model is part of the closed vehicle routing optimization system because of its starting and ending points. The amount of municipal waste per site was taken as the number of containers multiplied by the volume of the container. The volume of serviced containers is $1.1 \mathrm{~m}^{3}$, while the assumption of container filling is maximum fulfillment, i.e. that the amount of municipal waste in serviced containers is known in advance, which can be seen in Table 6. Travel time matrix representing the travel time from node $i$ to node $j$ and from node $j$ to node $i$ is shown in Table 7 .

Table 5 Coordinates and number of containers for the observed transport network

\begin{tabular}{cccc}
\hline $\begin{array}{c}\text { Location } \\
\text { number }\end{array}$ & Latitude & Longitude & $\begin{array}{c}\text { Number of } \\
\text { containers per } \\
\text { location }\end{array}$ \\
\hline Depo & 43.319256 & 21.919682 & 18 \\
2. & 43.322794 & 21.913082 & 17 \\
3. & 43.322464 & 21.914317 & 11 \\
4. & 43.324196 & 21.914412 & 8 \\
5. & 43.324696 & 21.916001 & 14 \\
6. & 43.323830 & 21.916709 & 21 \\
7. & 43.323338 & 21.917632 & 4 \\
8. & 43.322615 & 21.918220 & 9 \\
9. & 43.323829 & 21.921069 & 8 \\
10. & 43.322712 & 21.920759 & 4 \\
11. & 43.322109 & 21.922545 & 4 \\
12. & 43.321878 & 21.921097 & 15 \\
13. & 43.321168 & 21.917535 & 11 \\
14. & 43.322144 & 21.918179 & 12 \\
15. & 43.322471 & 21.915755 & 5 \\
16. & 43.319104 & 21.920206 & 8 \\
17. & 43.319854 & 21.920548 & 7 \\
18. & 43.320413 & 21.921150 & 11 \\
19. & 43.320076 & 21.922198 & 8 \\
20. & 43.320751 & 21.921739 & 8 \\
21. & 43.320552 & 21.923959 & \\
\hline
\end{tabular}


The collection of municipal waste is envisaged by one vehicle whose vehicle capacity is $Q=60 \mathrm{~m}^{3}$ and the time limit for the duration of the operated route is $T_{r i j}=60 \mathrm{~min}$.

Table 6 The estimated amount of waste per node

\begin{tabular}{lcccccccccc}
\hline Node & 2 & 3 & 4 & 5 & 6 & 7 & 8 & 9 & 10 & 11 \\
Demand $\left[\mathrm{m}^{3}\right]$ & 19.8 & 18.7 & 12.1 & 8.8 & 15.4 & 23.1 & 4.4 & 9.9 & 8.8 & 4.4 \\
\hline Node & 12 & 13 & 14 & 15 & 16 & 17 & 18 & 19 & 20 & 21 \\
Demand $\left[\mathrm{m}^{3}\right]$ & 4.4 & 16.5 & 12.1 & 13.2 & 5.5 & 8.8 & 7.7 & 12.1 & 8.8 & 8.8 \\
\hline
\end{tabular}

Table 7 Container emptying time per node

\begin{tabular}{lcccccccccc}
\hline Node & 2 & 3 & 4 & 5 & 6 & 7 & 8 & 9 & 10 & 11 \\
Emptying time $[\mathrm{min}]$ & 18 & 17 & 11 & 8 & 14 & 21 & 4 & 9 & 8 & 4 \\
\hline Node & 12 & 13 & 14 & 15 & 16 & 17 & 18 & 19 & 20 & 21 \\
Emptying time [min] & 4 & 15 & 11 & 12 & 5 & 8 & 7 & 11 & 8 & 8 \\
\hline
\end{tabular}

The vehicle has an upgrade to collect municipal waste with loading from its rear, while waste compaction is carried out using a pusher plate mechanism. During the search for optimal results based on the defined model DCCVRP-MCW, it is also important to note that, as it has been mentioned previously, the duration of one route is $60 \mathrm{~min}$.

In addition to limiting the duration of the routes, the time required to drive the vehicle from depot to landfill, emptying and returning to the depot is also provided. The approximate time needed for the vehicle to travel from the depot to the landfill, as well as emptying the collected waste and returning to storage is approximately $50 \mathrm{~min}$. Therefore, when the total time is summed up, it should not exceed the duration of one shift.

\section{Computational Results}

Based on the input parameters presented and the algorithms defined, the DCCVRPMWC model was summarized for each algorithm individually. It should be noted that the simulation of each algorithm was performed four times and the most optimal solutions were obtained. Regarding the implementation of GA, SA, PSO, ACO algorithms, the experimental results were tested in the MATLAB R2015a programming language, and numerical and graphical values were obtained on an HP ProBook 4530s computer with an Intel (R) Celeron CPU B840 @ $1.90 \mathrm{GHz}$ processor 1, $90 \mathrm{GHz}$ and 6GM RAM.

The route optimization of the given model presented in Chapter 2 and the transport network shown in Figure 4 was performed using meta-heuristic algorithms. The parameters of the algorithms used in this paper, as well as the obtained results, are presented in Table 8.

The parameters of the GA used to solve the DCCVRP-MWC are: maximum number iteration MaxIt $=500$, population size $\mathrm{nPop}=250$, mutation $\mathrm{Mu}=0.02$. The parameters of the PSO used to solve the DCCVRP-MWC are: MaxIt $=500$, population size nPop $=$ 250 , inertia weight $\mathrm{W}=1$, personal learning coefficient $\mathrm{c} 1=2$, global learning coefficient $\mathrm{c} 2=2.5$, total strength of the attractive terms alfa $=0.1$. The parameters of the SA used to solve the DCCVRP-MWC are: MaxIt $=500$, maximum number of inner iterations MaxIt2 $=300$, initial temperature $\mathrm{T}_{0}=100$, temperature reduction factor-alpha $=0.8$. 
The parameters of the ACO used to solve the DCCVRP-MWC are: MaxIt $=500$, the relative importance of trail alpha $=1.0$, the relative importance of visibility beta $=4.0$, parameter governing pheromone decay ro $=0.1$, we use ant cycle system, values for each parameter are max_cycl $=1$, constant that adjusts the speed $=5$.

Table 8 Parameters and results of GA, PSO, SA, ACO algorithm

\begin{tabular}{|c|c|c|c|c|}
\hline \multicolumn{5}{|c|}{ GA parameters } \\
\hline MaxIt & \multicolumn{2}{|c|}{ nPop } & \multicolumn{2}{|r|}{$\mathrm{Mu}$} \\
\hline 500 & \multicolumn{2}{|c|}{250} & & 0.02 \\
\hline \multicolumn{5}{|c|}{ GA results } \\
\hline Num. of routes & $\mathrm{T}_{\mathrm{rij}}(\min )$ & $\mathrm{Q}\left(\mathrm{m}^{3}\right)$ & & Routes \\
\hline 1 & 56.9000 & 53.9000 & & D -14-7-10-11-16-D \\
\hline 2 & 53.4667 & 59.4000 & & D-13-6-12-9-8-5-D \\
\hline 3 & 56.9400 & 57.2000 & & D-19-2-21-20-18-D \\
\hline 4 & 55.9000 & 52.8000 & & D-4-3-15-17-D \\
\hline$\Sigma$ & 223.2067 & 223.3000 & & \\
\hline \multicolumn{5}{|c|}{ PSO parameters } \\
\hline MaxIt & nPop & $\mathrm{W}$ & $\mathrm{c1}$ & alpha \\
\hline 500 & 250 & 1 & 2 & 0.1 \\
\hline \multicolumn{5}{|c|}{ PSO results } \\
\hline Num. of routes & $\mathrm{T}_{\mathrm{rij}}(\min )$ & $\mathrm{Q}\left(\mathrm{m}^{3}\right)$ & & Routes \\
\hline 1 & 56.5000 & 55.0000 & & D-17-15-7-11-16-D \\
\hline 2 & 56.9400 & 57.2000 & & D-18-20-21-2-19-D \\
\hline 3 & 51.2333 & 59.4000 & & D-13-6-12-9-10-8-D \\
\hline 4 & 58.3333 & 51.7000 & & D-5-4-3-14-D \\
\hline$\Sigma$ & 223.0067 & 223.3000 & & \\
\hline \multicolumn{5}{|c|}{ SA parameters } \\
\hline MaxIt & MaxIt2 & $\mathrm{T}_{0}$ & & alpha \\
\hline 500 & 300 & 100 & & 0.8 \\
\hline \multicolumn{5}{|c|}{ SA results } \\
\hline Num. of routes & $\mathrm{T}_{\mathrm{rij}}(\min )$ & $\mathrm{Q}\left(\mathrm{m}^{3}\right)$ & & Routes \\
\hline 1 & 51.5667 & 59.4000 & & D-10-11-12-9-6-13-D \\
\hline 2 & 58.3333 & 51.7000 & & D-5-4-3-14-D \\
\hline 3 & 54.0733 & 55.0000 & & D-19-20-21-2-16-D \\
\hline 4 & 58.3333 & 57.2000 & & D-18-17-15-7-8-D \\
\hline$\Sigma$ & 222.3067 & 223.3000 & & \\
\hline \multicolumn{5}{|c|}{ ACO parameters } \\
\hline MaxIt & alpha & beta & ro & max_cycl \\
\hline 500 & 1.0 & 4.0 & 0.1 & 1 \\
\hline \multicolumn{5}{|c|}{ ACO results } \\
\hline Num. of routes & $\mathrm{T}_{\mathrm{rij}}(\mathrm{min})$ & $\mathrm{Q}\left(\mathrm{m}^{3}\right)$ & & Routes \\
\hline 1 & 56.9400 & 57.2000 & & D-18-20-21-2-19-D \\
\hline 2 & 56.5667 & 58.3000 & & D-7-8-12-9-13-D \\
\hline 3 & 53.6333 & 56.1000 & & D-16-11-10-6-15-17-D \\
\hline 4 & 58.3333 & 51.7000 & & D-14-3-4-5-D \\
\hline$\Sigma$ & 225.4733 & 223.3000 & & \\
\hline
\end{tabular}


Using the SA algorithm, with the recommended parameters, four routes were obtained with a total duration of $222.306 \mathrm{~min}$. Figure 5 shows the design of the projected routes for the collection and transportation of municipal waste for a given transport network.

Figure 6 illustrates the relationship between route duration and vehicle occupancy per route for each algorithm. From the above picture, it can be seen that all the applied algorithms give good solutions and that the relation between route duration and vehicle occupancy is uniform. In this way, the validity of the application of all the algorithms used in this paper is confirmed.

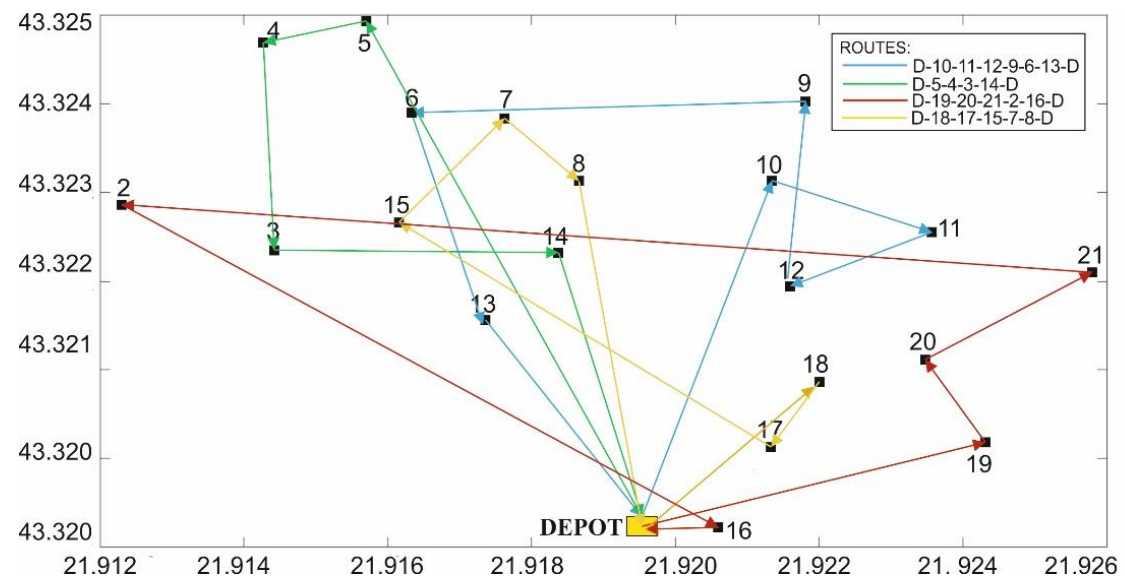

Fig. 5 Graphical representation of the routes of the models obtained with the SA algorithm

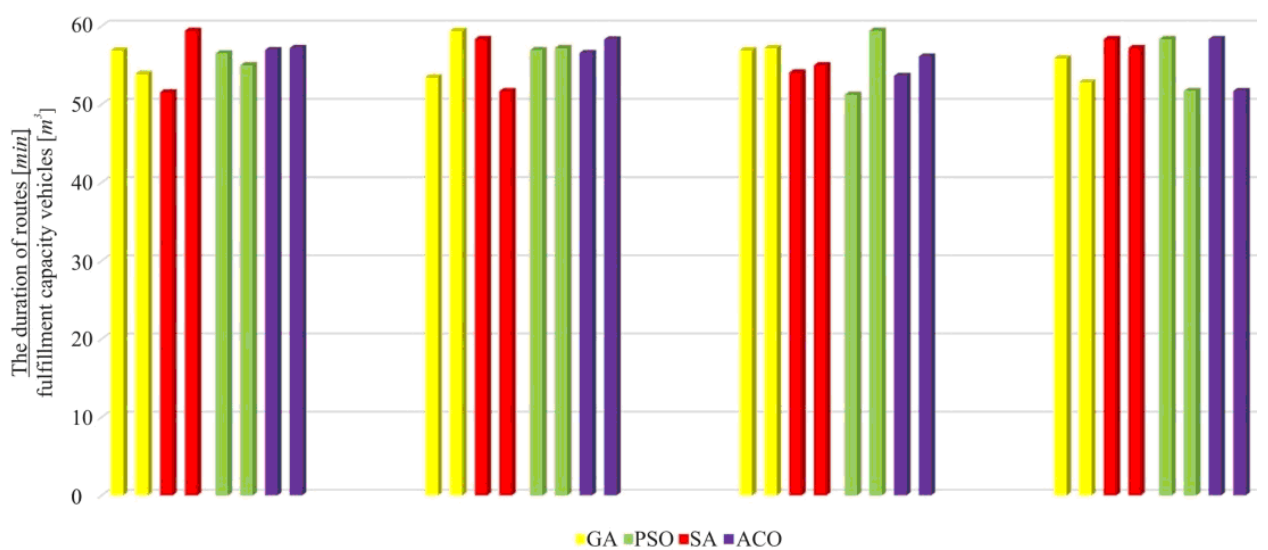

Fig. 6 The ratio of the duration of routes and the fulfillment capacity of vehicles 


\section{CONCLUSIONS}

The problem of municipal waste collection has been considered as a distanceconstrained capacitated vehicle routine problem - DCCVRP. The planning and optimization of municipal vehicle waste collection routes in urban areas fall within the operational level of an integrated waste management system. Optimization of waste collection and transportation routes is a permanent task of each utility company and this level of optimization should be controlled as a rule every 5 years. Properly designed routes (optimal routes) represent an important economic and environmental segment for any waste collection and transportation company. It is very important for the urban environment to properly design routes to reduce the effect of air pollution on the exhaust gases. This is especially important for the city of Nis, as municipal waste collection vehicles are rather used and old and the level of exhaust emissions is quite high.

The optimization of the DCCVRP-MWC by applying the meta-heuristic algorithms yielded routes of municipal waste collection and transportation vehicles for the observed transport network. The improvements obtained by the routes thus designed in comparison with the existing routes determined by the PUC "Mediana-Niš" are related to the reduction in the total length of the path and the reduction in the total operating time of the municipal waste collection vehicles.

These results show that by applying the proposed solution the mechanization fuel costs can be reduced by $10 \%$. In order to achieve an even greater reduction in municipal waste collection in urban areas, it is necessary to expand the problem and observe it in real-time. Such problems will be the subject matter of future research conducted by the authors of this paper.

Acknowledgement: This research was financially supported by the Ministry of Education, Science and Technological Development of the Republic of Serbia.

\section{REFERENCES}

1. A. Erdelez, J. Margeta, S. Kneziü, "An integrated approach to municipal waste collection system management”, Građevinar, vol. 59, no. 6, pp. 505-516, 2007.

2. G.B. Dantzig, J.H. Ramser, "The truck dispatching problem", Management Science, vol. 6, no. 1, pp. 80-91, 1959.

3. J. Teixeira, A. P. Antunes, J. P. de Sousa, "Recyclable waste collection planning-a case study", European Journal of Operational Research, vol. 158, no. 3, pp. 543-554, 2004.

4. G. Tavares, Z. Zsigraiova, V. Semiao, D. G. Carvalho, "Optimisation of MSW collection routes for minimum fuel consumption using 3D GIS modelling", Waste Management, vol. 29, no. 3, pp. 1176-1185, 2009.

5. D. Marković, G. Petrović, S. Marković, "Distance-Constrained Capacitated Vehicle Routing Problems: Case Study and Simulated Data Set", The sixth international conference transport and logistics til2017, Niš, Serbia, 2017, pp.308-313.

6. D. Marković, G. Petrovć, Ž. Ćojbašić, A. Stanković, "The vehicle routing problem with stochastic demands in an urban area-a case study", Facta Universitatis, Series: Mechanical Engineering, Vol 18, No 1, pp. 107-120, 2020, DOI:10.22190/FUME190318021M

7. F. W. Glover, G. A. Kochenberger, Handbook of metaheuristics, International Series in Operations Research \& Management Science, vol. 57. Springer Science \& Business Media, 2003.

8. A. Stanković, D. Marković, G. Petrović, Ž. Ćojbašić, "Simulated annealing and particle swarm optimization for the vehicle routing problem and communal waste collection in urban areas", 14th International Conference on Accomplishments in Mechanical and Industrial Engineering, DEMI 2019, Banja Luka, Republic of Serbia, 2019, pp. 497-505. ISBN: 978-99938-39-84-2, Banja Luka, 24 - 25 May 2019. 
9. D. Marković, A. Stanković, G. Petrović, M. Trajanović, Ž. Ćojbašić, "Genetic and Ant Colony Optimization Based Communal Waste Collection Vehicle Routing", 9th International Conference on Information Society and Technology will be held on Kopaonik, Serbia on Mar 10-13, 2019, pp. 209-212.

10. R. Eshtehadi, E. Demir, Y. Huang, "Solving the vehicle routing problem with multi-compartment vehicles for city logistics", Computers \& Operations Research, vol. 115, 2020, https://doi.org/10.1016/j.cor.2019.104859.

11. J. Brito, F. J. Martínez, J. A. Moreno, J. L.Verdegay, "An ACO hybrid metaheuristic for close-open vehicle routing problems with time windows and fuzzy constraints", Applied Soft Computing, vol. 32, pp. 154-163, 2015.

12. J. H. Holland, Adaptation in Natural and Artificial Systems. University of Michigan Press, Ann Arbor, 1975.

13. Ž. Ćojbašić, M. Ristanović, N. Marković, S. Tešanović, 'Temperature controller optimization by computational intelligence", Thermal Science, vol. 20, no. 5, pp. 1541 - 1552, 2016.

14. X. S. Yang, Engineering Optimization: An introduction with metaheuristic applications. University of Cambridge, United Kingdom, 2010.

15. J. Kennedy, J. R. Eberhart, "Particle Swarm Optimization", Proceedings of the IEEE International Conference on Neural Networks, pp. 1942-1948, 1995.

16. A. Jin, K. Voratas, "Particle swarm optimization and two solution representations for solving the capacitated vehicle routing problem", Computers \& Industrial Engineering, vol. 56, no. 1, pp. 380-387, 2009.

17. G. A. Di Caro, F. Ducatelle and L. M. Gambardella, "Ant colony optimization for routing in mobile ad hoc networks in urban environments," Dalle Molle Inst. for Arti-ficial Intell., Manno, Switzerland, Rep. May, 2008.

18. A. Colorni, M. Dorigo, V. Maniezzo, "Distributed Optimization by Ant Colonies", Proceedings of ECAL'91Proceedings of the European Conference on Artificial, Paris, Elsevier Publishing, Amsterdam, 1991, pp.134-142.

19. S. Kirkpatrick, C. Gelatt, M. Vecchi, “Optimization by Simulated Annealing”, Science, vol. 220, no. 4598, pp. 671-680, 1983

20. M. Madić, Mathematical modeling and optimization of laser cutting process using artificial intelligence methods. PhD Thesis, University of Niš, Faculty of Mechanical Engineering, 2014.

\section{METAHEURISTKA ZA PROBLEM USMERAVANJA VOZILA ZA SAKUPLJANJE KOMUNALNOG OTPADA U URBANOJ SREDINI}

Ovaj rad predstavlja metodologiju rešavanja problema sakupljanja komunalnog otpada u urbanim sredinama. Ovaj problem je tretiran kao problem usmeravanja vozila sa ograničenim rastojanjem za sakupljanje komunalnog otpada (DCCVRP-MVC) i spada u grupu problema kombinatorne optimizacije. Da bi se rešio ovaj problem korišćena su četiri meta-heuristička algoritma i to: Genetski algoritam (GA), Simularno kaljenje (SA), Optimizacija rojem čestica (PSO) i Optimizacija kolonijom mrava (ACO). Usmeravanje vozila igra veoma veliku ulogu u velikim transportnim kompanijama koje se bave prevozom ili transportnom komunalnog otpada, stoga je u radu predlažen jedan od nekoliko algoritama za rešavanja problema sakupljanja komunalnog otpada u urbanim sredinama.

Ključne reči: problem usmeravanja vozila, komunalni otpad, meta-heuristika, logistički model. 